\title{
Using CRISPR/Cas9 for generation the cd209 knockout is a way to get cattle breeds resistant to the Bovine leukemia virus (BLV)
}

\author{
Alexey $V$. Deykin ${ }^{123^{*}}$, Marina $V$. Kubekina ${ }^{1}$, Yulia Yu. Silaeva ${ }^{1}$,Anna $S$. Krivonogova ${ }^{4}$, and \\ Albina $G$. Isaeva ${ }^{4}$ \\ ${ }^{1}$ Core Facility "Genome editing", Institute of Gene Biology of the Russian Academy of Sciences, \\ 119334, Vavilovast., 34/5, Moscow, Russia \\ ${ }^{2}$ Center of Precision Genome Editing and Genetic Technologies of Biomedicine, Institute of Gene \\ Biology of the Russian Academy of Sciences, 119334, Vavilovast., 34/5, Moscow, Russia \\ ${ }^{3}$ Laboratory of Pathogenomics and Transcriptomics, Institute of General Pathology and \\ Pathophysiology, 125315, Baltiyskayast., 8, Moscow, Russia \\ ${ }^{4}$ Ural Federal Agricultural Scientific Research Center of Ural Department of Russian Academy of \\ Sciences, 620142,Belinskogost.,112 A, Ekaterinburg, Russia
}

\begin{abstract}
Bovine leukemia virus (BLV) causes enzootic leukemia - a chronic infectious disease occurring against the background of embedding the virus in the genome of B-lymphocytes and leading to malignization, invasion of tumor cells in organs and the formation of tumors. The disease is common in the United States, Japan, and Asia. In Russia, up to $30 \%$ is infected with BLV. Moreover, there is evidence of the presence of antibodies to the BLV virus in some groups of people, and the relationship between BLV and cancer in humans is widely discussed. All this indicates an urgent need to study BLV and create breeds resistant to it. The development of approaches to solving this problem is complicated by the fact that the receptor through which the infection is carried out is still unknown. Recently, it has been suggested that the virus penetrates the animal's lymphocytes using the CD209 molecule. In this paper, we propose a genome editing system based on CRISPR/Cas9 to get a knockout for this gene. We assume that animals obtained using the presented genome editing system will be resistant to infection with the bovine leukemia virus.
\end{abstract}

\section{Introduction}

Bovine leukemia virus (BLV) is an oncogenic virus of the deltaretrovirus family, close to the human T - cell leukemia virus [1]. In Russia, a significant part of livestock is infected with BLV, which causes significant damage to agriculture. In addition, there is no convincing evidence that it is impossible to infect humans with BLV through the milk and meat of infected animals [2]. Thus, obtaining cattle breeds that are resistant to BLV would solve a very urgent problem of modern agriculture. The development of approaches to

*Corresponding author: deikin@igb.ac.ru 
solving this problem is complicated by the fact that the receptor through which the virus is able to permeate the lymphocytes is not known yet.

Recently, a number of possible candidates for this role have been identified. Thus, it has been suggested that the CAT1/SLC7A1 molecule may be a receptor for BLV [3]. However, the most likely hypothesis presented in a recent paper [4] is that the CD209 molecule is a potential receptor for the bovine leukemia virus. Moreover, mutations in the $c d 209$ gene are associated with resistance to infection with the human T-cell leukemia virus [5]. In this paper, we present a crispr/Cas9-based cattle genome editing system for creating a $c d 209$ knockout. We assume that using this approach will allow us to obtain a relatively fast population of animals that are resistant to infection with the bovine leukemia virus $[6,7]$.

\section{Materials and methods}

Guide RNA cloning was performed in the px330 vector (Addgene, https:/www.addgene.org/crispr/zhang/) in accordance with the manufacturer's instructions. The vector was cut using BbsI-HF restrictase (New England Biolabs), dephosphorylated using FastAP enzyme (Thermofisher Scientific), then purified in agarose gel and then isolated using the Monarch DNA Gel Extraction Kit. Oligonucleotides containing a sequence of guide RNAS were synthesized by Eurogen.

\section{5' - CACCGNNNNNNNNNNNNNNNNNNN - 3'}

3' - CNNNNNNNNNNNNNNNNNNNCAAA - 5'

Scheme of oligonucleotide synthesis for cloning guide RNA. Added nucleotides to complement the sticky ends formed when cutting the px330 vector with BbsI-HF restrictase $[8,9]$.

The oligonucleotides were phosphorylated using the PNK kinase enzyme (Thermofisher Scientific), annealed with each other, and ligated with the previously prepared vector and using the T4 DNA ligase enzyme (Thermofisher Scientific). The ligase mixture was transformed into competent cells of the XL1blue strain (Eurogene). The colonies were screened using Isogen PCR kits. Two colonies each containing sgrna were grown in the night culture and isolated using the Monarch Plasmid Miniprep Kit. Sequencing of the obtained plasmids was performed using the U6-forv primer by Eurogen. The sequencing analysis was performed using SnapGene software.

The research is executed at the expense of a grant of the Russian scientific fund (project No. 19-76-10022).

\section{Results}

To create a knockout of the $c d 209$ gene, it was decided to introduce a mutation into the second exon of this gene $[10,11]$. Table 1 shows several potential sgRNAs for introducing a mutation to the second exon of the $c d 209$ gene. The fifth one was selected ( $93 / \mathrm{fw}$ ), since it has the least number of off-target sites associated with it compared to the other results of the CRISPOR - Tefor program analysis. The first $\operatorname{sgRNA}(71 / \mathrm{rev})$, which has the same number of offtargets, was not accepted, because when working with it, it is not possible to make a mutation in its PAM site without changing the amino acid (Proline).

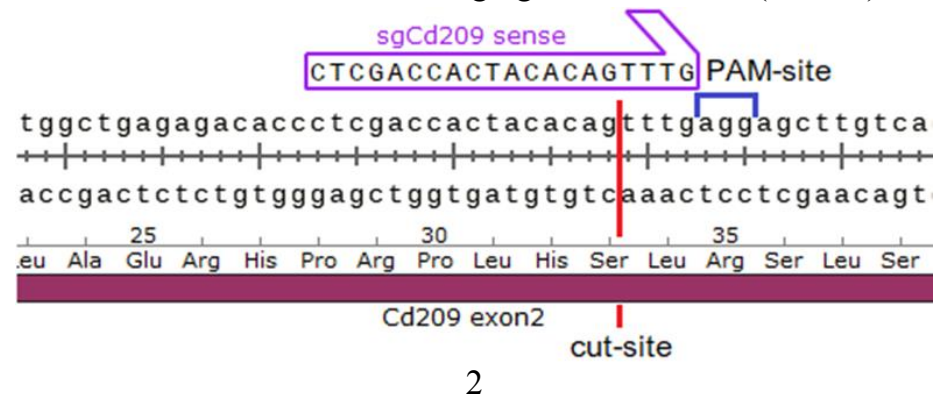


Fig. 1. Diagram of making a cut in the second exon of the $c d 209$ gene using the CRISPR/Cas9 system.

Table 1. potential sgRNAs for introducing a mutation to the second exon of the $c d 209$ gene.

\begin{tabular}{|c|l|c|c|l|}
\hline $\begin{array}{c}\text { Position/ } \\
\text { Strand }\end{array}$ & \multicolumn{1}{|c|}{ Guide Sequence + PAM } & $\begin{array}{c}\text { MIT Specificity } \\
\text { Score }\end{array}$ & $\begin{array}{c}\text { CFD Spec. } \\
\text { score }\end{array}$ & $\begin{array}{c}\text { Off-targets for } \\
0-1-2-3-4 \\
\text { mismatches }\end{array}$ \\
\hline $71 / \mathrm{rev}$ & $\begin{array}{l}\text { TCAAACTGTGTAGTGGTCGA } \\
\text { GGG }\end{array}$ & 91 & 94 & $\begin{array}{l}0-0-2-4-46 \\
52 \text { off-targets }\end{array}$ \\
\hline $72 / \mathrm{rev}$ & $\begin{array}{l}\text { CTCAAACTGTGTAGTGGTCG } \\
\text { AGG }\end{array}$ & 90 & 94 & $\begin{array}{l}0-0-0-8-55 \\
63 \text { off-targets }\end{array}$ \\
\hline $125 / \mathrm{fw}$ & $\begin{array}{l}\text { GGTACGGGAGTGCTTGGTTC } \\
\text { AGG } \\
\text { Inefficient }\end{array}$ & 88 & 96 & $\begin{array}{l}0-0-0-8-49 \\
57 \text { off-targets }\end{array}$ \\
\hline $119 / \mathrm{fw}$ & $\begin{array}{l}\text { TTGTCAGGTACGGGAGTGCT } \\
\text { TGG }\end{array}$ & 87 & 93 & $\begin{array}{l}0-0-0-6-59 \\
65 \text { off-targets }\end{array}$ \\
\hline $93 / \mathrm{fw}$ & $\begin{array}{l}\text { CTCGACCACTACACAGTTTG } \\
\text { AGG }\end{array}$ & 84 & 94 & $\begin{array}{l}0-0-0-4-48 \\
52 \text { off-targets }\end{array}$ \\
\hline
\end{tabular}

5 annual RNAs for introducing a mutation in the $c d 209$ gene shows in table 1. Figure 1 show the diagram of making a cut in the second exon of the $c d 209$ gene using the CRISPR/Cas9 system.

Analysis of plasmid sequences with the sgRNA sequence shows that the cloning was successful and the sequence fully corresponds to the expected one (Figure 2)).

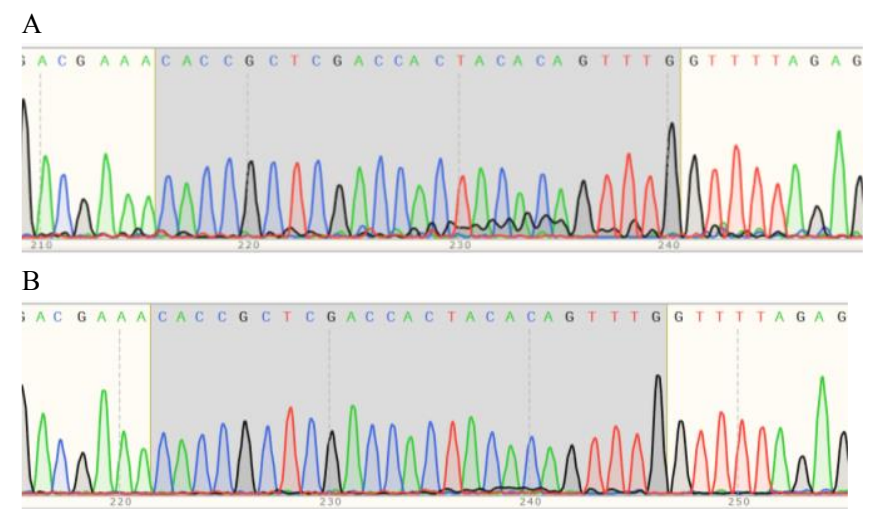

Fig. 2. Sequence analysis of two (A and B) clones of plasmids pX330-CD209.

\section{Conclusion}

We performed bioinformatic analysis of the cattle genome in the area of $c d 209$ gene localization, analysed the sequences of potential target RNAS for the gene editing system, selected the most specific ones, and performed molecular cloning and Sanger sequencing analysis of the quality of the obtained structures. Thus, a system for editing the cattle 
genome using CRISPR/Cas9 has been developed to create animals that are knocked out by the $c d 209$ gene. We assume that the resulting animals will be resistant to BLV infection, which will improve the epizootic situation and the safety of livestock products.

\section{References}

1. M. Polat, S.N. Takeshima, Y. Aida, J. Virol, 14 (1), 209 (2017)

2. G.C. Buehring, H.M. Sans, Int J Environ, Res Public Health, 17 (1), 209 (2019)

3. L. Bai, H. Sato, Y. Kubo, S. Wada, Y. Aida, FASEB J., 33 (12), 14516-14527 (2019)

4. E.A. Klimov, A.A. Shevtsova, S.N. Kovalchuk, Science, technology and education, 9 (50), 23-27 (2018)

5. P.E. Ceccaldi, F. Delebecque, M.C. Prevost, A. Moris, J.P. Abastado, A. Gessain, O. Schwartz, S. Ozden, J Virol, 80 (10), 4771-80 (2006)

6. O.G. Maksimenko, A.V. Deykin, P.G. Georgiev, Acta Naturae, 1 (16), 5 (2013)

7. A.V. Deykin, Russian Scientist, 1 (2), 16-17 (2017)

8. T.V. Dimitrieva, et al., Bulletin of Russian State Medical University, 3, 16-22 (2016)

9. T.V. Egorova, et al., Diseasemodels \& mechanisms, 12 (4) (2019)

10. V.A. Kalmykov, et al., Research Results in Pharmacology, 4 (4) (2018)

11. Y.Y. Silaeva, V.A. Kalmykov, E.A. Varlamovaet al, DoklBiochemBiophys, 490, 43-46 (2020) 